\title{
Assessing the convergence of scenic preferences for highland scenes using photographic survey and interview methodologies
}

\begin{abstract}
The study was conducted at the Cameron Highlands, Malaysia. This paper evaluated the convergence of results obtained from the assessments of scenic preferences using two methods; photography survey and interview. The goal of the study was to determine the similarity in scenic preferences when using two methods with different groups of respondent. The respondents of the photography survey were the tourists of Cameron Highlands, while the respondents of the interview were the local residents. An exploratory field observation was carried out at the study areas in order to identify the possible scenic indicators. The scenic indicators identified were natural beauty, and land use. Based on these indicators, a photographic inventory was conducted at the study areas. A pool of experts was asked to classify each scene in each photograph using these two indicators. A total of 12 classified photographs were selected for the photography survey. Tourists of Cameron Highlands were asked to rank their scenic preferences using a ranking scale 1-12; rank 1 was the most preferred, while rank 12 was the least preferred. Results show that the tea plantation was the most preferred scene (rank 1); the next preferred scenes were the natural hill (rank 2), waterfall (rank 3), and natural forest (rank 4). The least preferred scene was the commercial development (rank 12). The next least preferred scenes were the residential housing (rank 11), vegetable farm on terraced land (rank 10), flat landscape (rank 9) and vegetable farm on flat land (rank 8). A semi structured interview was used to determine the scenic preferences of the local residents. Results show that the tea plantation was the most preferred scene (rank 1). The next preferred scenes were the natural forest (rank 2) and hill (rank 2). The least preferred scene was the vegetable farm (rank 5). The next least preferred scenes were the waterfalls (rank 4) and residential housing (rank 4). The results indicate that the patterns of scenic preferences for highland scenes between the tourists and the local residents have close similarity. In conclusion, the results generated from both methods can be accepted for the future decision in the highland management, since both results point towards similar scenic preferences.
\end{abstract}

Keyword: Convergence; Highland scenes; Scenic indicators; Scenic preference; Local resident; Tourists 